A STRONOMY, cradled in super$\mathrm{A}_{\text {stition, and fed in infancy by the }}$ fears of kings, only became a science when it dissociated itself from astrology and restricted itself to matters capable of mechanistic interpretation. Other sciences, including most fields of medicine, have likewise weaned themselves from their infant diets of credulity and crude utility. In consequence, chemistry, mathematics and physics have become reputable disciplines whose general scope and aim could not be misrepresented in public documents without exciting wide comment.

Why is the genetics of man not accorded the standards of public scrutiny and stock-taking normally afforded to radioastronomy, high-energy physics, and the genetics of flies? It can hardly be mere difficulty, for the basic mechanisms of genetics are, in principle, far simpler than those invoked for stars and atoms, and the genetics of man is only marginally more remarkable than that of the fly. Until we can diagnose the cause of this contagious mediocrity we cannot expect any cure, and without some attempt at cure we cannot expect that workers of the calibre expected in those who listen to the skies, or look for portents in bubble chambers, will be attracted to this field. The reputed mediocrity of physicians, a belief widespread among those who are not physicians, is hardly a reason, for immunology, virology, and numerous other specialised fields in and around medicine are progressing well.

The reason must be in ourselves. While we can accept, after many generations, the peripheral isolation of the Earth, and even the Sun, the full implications of evolution and of natural variability are too much. Genetic disorders are rare, and only a minority are amenable to elimination, to prevention, or to treatment. They have been with us throughout our evolution, and most are likely to stay with us for as long. They require the same basic facilities for research, for diagnosis, for treatment, and even for elimination, as do other forms of disease.

Genetic disorders are, by definition, those to which the flesh is heir, and cover all disease. In practice it is convenient to use the word 'genetic' to cover those disorders consequent upon some hereditary unit, or pair of units, which is usually either sufficient, or necessary, for the manifestation of disease, as in the genic and chromosomal disorders. Victims include those who, by chance, were conceived without the alleles necessary for synthesising pigment in the eye and skin, or, by mischance, were conceived with the handicap of an extra chromosome.

Even here words can be confusing, for albinos rarely have inherited any noticeable disorder from their ancestors, and those burdened by an extra chromosome are usually born to parents with a regular allocation. But the term genetic, implying an inborn qualitative or quantitative abnormality in their nuclear apparatus which is sufficient to cause distress, is useful and rarely ambiguous. Obviously, the environment will influence affliction, but, within any regular environment, any inability to cope with minor injury, sunlight, or conventional food can be a sufficient handicap to qualify for the term 'disease'.

\section{Genetic facts?}

Once the word genetic is extended to cover any inborn predisposition, whether to illness, to aptitude, or to crime, difficulties arise which can only be removed by a less casual use of words. A recent publication from the US National Institute of General Medical Sciences, National Institutes of Health, (What are the facts about genetic disease?, with the strange subtitle, Most ubiquitous of all human maladies) does nothing to lighten the genetic load of confusion, and its authors have done a serious disservice to those-many of whom are featured in photographs in this booklet-who are striving for an orderly application of genetic knowledge to man.

The book tell us (p. 6) that 15 million Americans have birth defects, and that $80 \%$ of these "carry true genetic diseases due wholly or partly to defective genes or chromosomes". The genetic load is then elaborated to cover 100,000 abortions and $40 \%$ of infant deaths; each of us (presumably US citizens) carries "between five and eight recessive genes for serious genetic effects" and each married couple has a $3 \%$ risk of having a genetically defective child. The opposite page is a little less exact with recessives, giving the range as "between one and ten", and shows some normal looking individuals and a superimposed pedigree of the extremely rare and variable Hartnup disease, stating that the normal siblings are at risk of transmitting it to their offspring-a risk too low to justify anxiety, or even the use of the word risk.

Next, disorders of infancy are shown to cause more lost years of life than disorders of the aged. Single gene defects are said to occur in 1.8 to $2 \%$ of all births. But the "overall incidence of recognised genetic diseases is 4.8 to $5.0 \%$ of all live births", a curiously exact estimate, but one which seems out by a factor of 10 . We are told that "authorities now estimate that seven to eight per cent of the US population is adversely affected by one or another form of heritable disease" (p 14) while the next page includes gout and diabetes as genetic diseases, which certainly helps the percentages. We are probably all potential diabetics. Heart disease emerges again on page 21: this time $20 \%$ of cases are attributable to one of three genes and $5 \%$ are polygenic (what about the other $75 \%$; can anything be non-genetic and non-polygenic?). Those three unspecified genes are said to be the most common disease-producing genes. Estimates of hard cash are made with equal abandon. Death from Tay-Sachs disease is costed at $\$ 35,000$, which seems a lot unless it includes the artificial piping of both food and air to the dying. Earlier, the booklet states that "specific genetic factors are involved in approximately one-fifth of all heart attacks". What does this mean? Why not incriminate the $\mathrm{Y}$ chromosome, which is surely genetic, and is found in at least four fifths of victims of heart attack?

How can the economic custodians of medical research in a country which has such numerous claims to excellence in both aim and achievement, be associated with the publication of such a confused and contradictory document? For whom can it be meant? Why are the achievements made by other routes, such as safe blood transfusion, the 'cure' of rhesus disease by exchange transfusion, and its prevention by immunisation, not worthy of mention? Are not the triumphs of haemophiliac therapy worth a sentence? The US decision to funnel funds into 10 centres seems strange, since excellence cannot be constrained, even in smaller countries; is this booklet for congressmen who think their constituents neglected? Or is it what the Observer calls "research by public hysteria"?

Genetic research needs money, and the excellence of this research in the US would seem to have suffered even more than that in most other countries during recent years. A pre-occupation with costing, with short term aims, and the throwing around of wild estimates of such measures of the genetic load as the number of recessives per gamete, or the number of dollars per death, does little to reassure admirers of American genetics that the future will be worthy of the past.

It is tempting to dismiss this as a mere manifestation of bureaucratic immaturity, hardly worthy of comment. The matter is however, too important to be glossed over in this way. There is nothing more important than the orderly survival and civilisation of our own species. 